\section{THE INSTITUTES OF SURGERY.}

\section{AN HISTORICAL REVIEW.}

BP

SIR BERKELEY MOYNIHAN, C.B., M.S., F.R.C.S., Professor of Clinical Surgery in the Univergity of Leeds; Temporary LieUtenant-Colonet R.A.M.C.

Men, it is said, are apt to be taken at their own valuation. What is true of a man may be true of a nation. It is beyond dispute that Germany, as a result, in part, of the arrogant repetition of her claim to intellectual superiority over all nations, and in part, of a tolerant and sometimes disdainful silence or acquiescence by others, has been accepted almost universally as the pivot and centre of the world's thought. My own realization of this, in regard to surgical matters, was dramatic in its suddenness. I had been a student in Germany years ago, had lived with German students, and followed closely the work of German surgeons in several clinics. I had formed my own conclusions as to the value of the German contributions to sur gical advancement, and nothing that has happened since the war began has altered in any way the opinions I then held. About five years ago one of the most distinguished of the Scandinavian surgeons, who had made a yearly pilgrimage to Germany of some weeks' duration, came to spend his surgical holiday in England. He lived with me for more than a month. I had always known him as a warm advocate of Germany's methods in surgical hiterature and practice, and of his intellectual contempt for most of the things which other nations had done. Of the work of these other nations he had learnt nothing at first hand; the little he knew had been distilled through the minds of German interpreters, and had been conveyed to him verbally on his frequent visits, or had been taken from the easily accessible German journals and textbooks. At our first brealfast meeting he told me of his immense obligations to Germany, of his schooling in her methods, of his devoted attention to the debates of the German Surgical Association; and he went on to say that he felt it almost an act of treachery to spend his surgical vacation in any other land. And then he gravely announced that "Of course all surgical advance in the last fifty years has come from Germany." To that kind of fervid unrestrained assertion the most fruitful denial is given by a questioning assent. I answered: "Of course; tell me of one." Whereupon I had to learn from him that the introduction of the antiseptic system into practice was wholly to be attributed to German research, adoption, and adrocacy. Now this claim so confidently made, and, I hope I may say, so utterly shattered in the debate which followed, is precisely the type of claim which Germany herself has always made. Most of the great ideas, she tells us, originated with her; those that by chance arose elsewhere would never have come to fruition but for her acceptance, and for the authority with which thereby they were endorsed.

\section{Antiseptics.}

Of the facts as to the discovery of the antiseptic system there is, of course, no dispute. They begin with the dis. covery in 1836 by Latour of the living character of the yeast ceils by which fermentation was produced. This discovery, it is interesting to recall, was denied both by Liebig and by Helmholtz. The confirmation and exten sion of this work by Pasteur in 1856 showed that putre faction and fermentation were the result of living particles and that for each type of fermentation a specific particle was nesessary. "The most far-reaching of my researches," said Pasteur, "is simple enough ; it is that putrefaction is produced by living ferments." He asserted that the oxygen of the air was not the cause of putrefaction, as every one hitherto had supposed; that, indeed, some of the causes of decomposition could thrive only in the absence of oxygen. This observation, too, which dis. tinguishes "aërobic" from "anaërobic" organisms, is of the first importance. It was these discoveries which suggested to Lister the thought that the putrefactice changes in wound discharges might be due to living organisms; and that the exclusion of these would enable wounds to heal without the formation and corruption of purulent discharges.

In 1867 Lister wrote: "When it had been shown by the researches of Pasteur that the septic property of the atmosphere depended, not on the oxygen or any gaseous constituent, but on the minute organisms suspended in it which owed their energy to their vitality, it occurred to we that decomposition in the injured part might be avoided, without excluding the air, by applying as a dressing some material capable of destroying the life of the floating particles.'

A discovery is rarely the work of one mind. It is one observation added to another that makes the supersaturated solution from which the crystal of truth at last precipitates. Lister never ceased to give credit to Pasteur for his share in the work that led finally to the development of the antiseptic method. The exploratory work, the pioneer work, all that was original, was done therefore by a French observer and an English surgeon. The exploitation of this work, it is true, was almost at once eagerly and widely carried out by the surgeons of Germany. The system was examined, appraised, and adopted throughout the whole empire of Germany; but so it was elsewhere. Lister never had a more ardent, a more scrupulous and conscientious pupil than Lucas. Championnière. Up to his death this veteran French surgeon carried out with meticulous care exactly those procedures which he had learnt from Lister. But the loud shouting in support of the antiseptic treatment came chiefly from Germany. When in 1875 Lister visited that country his progress was a triumpl. It is notorious, however, that in carrying the Listerian principles to their lo yical conclusion in practice, Germany fell far behind other countries. In recent times has any surgeon visited Germany to learn a good technique? Is it not true to say that those surgeons of whom one heard most in the world, great teachers and writers as they doubtless were, were lacking in the very rudiments of a sound and careful method? There was not, I truthfully believe, one surgeon in the whole German empire who looked upon an opera. tion as an experiment in bacteriology, and who to avoid infection in ilis wounds used scrupulous care in the preparation and manipulation of his instruments and materials, who avoided chance contamination, and who used extreme gentleness and delicacy of touch as modes of avoiding that form of trauma which makes infection easy. And the average display of a technique called aseptic or antiseptic was something immeasurably below the standard of some surgeons in England and of many in America. Even in the method they so ardently exploited, and in a field they claimed as their own, they fell far short of the best. This example is typical of many. All modern surgery, as we know, dates from Lister. The difference between the surgery of ancient days and the surgery we practise to-day is expressed in one word, "Lister."

Of all the advances made in surgery the most fruitful and the most interesting is that which depends upon a study of the "pathology of the living." Lister made it possible to operate with safety upon conditions which threatened life, or made it almost unendurable-such, for example, as ovarian cyst. And by degrees, as methods were perfected and experience widened, other diseases could be attacked, at first in their terminal or more dramatic manifestations, as in the perforation of gastric or duodenal ulcers; and later in their pathological career as disturbers of function or of health, before the later complicaticns had had time to develop. It is interesting to note that the first surgical attack upon many diseases afflicting the abdominal viscera has been made when terminal events have rudely developed, and when therefore the surgical hazards were greatest. It was only in later days that the deliberate operations for initial stages of the same disease were brought within the province of the surgeon.

The Appeal to Nature.

When we review the wonderful and varied achievements of medicine it is not easy to fix a time at which the science and the art of surgery, as we think of them to-day, began to develop. As we look back we realize that it is because of the work of Vesalius the anatomist, of Harvey the physiologist, of Morgagni the father of pathology, and later of John Hunter, the first of scientific surgeons, that all subsequent advances were made possible. From the rude efforts of the early and mediaeval surgeons the first real step forward was made by Ambroise Paré, who stands conspicuous above all his contemporaries at the time of the Renaissance. Betwcen Paré and Hunte: probably only one surgeon was of serious consequence in the progress of our 
ait. This was Richạrd Wiseman, a man "given to the observation of nature," who was the first to advocate and practise primary major amputations. Till the days of Hunter surgery produced, it is true, great or successful individual practitioner's, but there was little or no progress in the scientific work upon which the craft must always be based.

It was Hunter in England, and Bichat in France, who went to original sources for their knowledge. Hunter wrote of himself, "I am not a reader of bools," and "I believe nothing I have not seen and observed muself." His prodigious industry, his intellectual rapacity, his vast store of first-hand observation, and his simple attitude as a student all his life, are not equalled in the history of Medicine. Harvey had said of himself that he felt it in some sort criminal to call in question doctrines that had descended through a long succession of ages and carried the authority of the ancients, but he "appealed unto Nature, that bowed to no antiquity, and ras of still higher authority than the ancients." With Hunter it was quite different. His eager inquiry was always for the story as it was written by disease upon the tissues of the dead body. His information was always first hand, gleaned from every source, with unvearying patience and untiring zeal. His disregard of written words and of ancient authors was deplorable no doubt, but a striking and authentic characteristic nevertheless. His reply, when taunted with ignorance of the classics, is famous: "Jesse Foot accuses me of not understanding the dead languages, but I could teach him that on the dead body which he never knew in any language, dead or living." He was the bor'n collector, possessed of an insatiable appetite for knowing rather than wondering, and for seeing rather than reading or hearing of another's work. No man ever suffered less from the tyranny of the written word; no man ever searched more diligently or in humbler mood for those eternal sources of the truth upon which alone a science of medicine can be founded, and from which alone it can be continually refreshed. Hunter realized, as Paré and Franco before him had done, as every great original thinker since has done, that the foundations of true progress in scientific work are laid cleep, that it is "from the depths, not from the lieights, that medicine is fed ; from the springs, not from the sky." 'The impetus and the authority given to surgical work by the researches of Morgagni, of Bichat and of Hunter were incalculable. 'The time was gone for ever when a pure and dangerous empiricism coula be practised; surgery became a rational procedure, and its new ventures were held in restraint, as we now realize, only by the fear, or rather the certainty, of inflammatory complications more immediately daugerous than the disease from which relief was sought.

For the groundwork of medicine and of surgery, there fore, Germany was in no degree responsible. It was Vesalius of Brussels who laid solid the foundation of anatomy, in a treatise remarkable alike for the accuracy of the descriptions and for the beauty of the illustrations, which came perhaps from the studio of Titian. It was Harrey, our own countryman, who, by his immortal dis covery, swept a way the decaying fragments of Galenism, and made possible all later researches in physiology. It was Morgagni, the Italian, who brought together the statics and dynamics of medicine, who founded pathology, the science of the causes of error in the working of the liuman machine, and who explained symptoms by assigning then to structural alterations in the several organs of the body. It was Hunter who changed surgery from a handicraft to an art based upon an accurate knowledge of diseased tissues, who first made of surgery a science. It was Pasteur, the Frenchman, who guided Lister to his dis covery of antiseptic surgery, which has changed the whole luistory of our science and craft. It was Morton and Warren of Boston, and Simpson of Edinburgh, who, by the discovery of ether and of chloroform, robbed surgery of its agony and horror and made it accessible as well as possible. To all these weighty matters, to all the in dispensable achievements without which medicine could have made no advance, it is the simple truth to say that Gcrmany gave nothing.

\section{Abdominal Surgery.}

The first great surgical adventure of modern times was ccncerned with the removal of ovarian cysts. The history of ovariotomy is well known, but will bear at this moment a brief repetition. Removal of the ovaries in animals and in aborigines has been practised from prelistoric times. In the literature of the middle ages several curt references were made to "dropsical ovaries"; and opinions were expressed that operative measures might sometimes be undertaken with a remote chance of cure. The first successful case was operated upon in 1701 by Houston of Glasgow ; the patient lived till 1717 . John Hunter wrote in 1785: "I cannot see any reason why, when the disease can be ascertained in an early stage, we should not make an opening into the abdomen and extract the cyst itself." Before this William Hunter had written, in 1762: "It has been proposed by modern surgeons, deservedly of the first reputation, to attempt a radical cure by incision or suppuration, or by excision of the cyst." The first surgeon, however, to whom the world's credit and applause are due for establishing the operation as a proper and safe procedure was McDowell of Kentucliy, an old pupil of John Bell in Edinburgh, by whose teaching he was inspired. McDowell's first case was operated upon in 1809; the patient lived till 1814. Between 1809 and his death in $1830 \mathrm{McD}$ owell operated upon ovarian tumours in thirteen cases, and it is lmown that eight patients recovered. After his day the operation fell into disrepute, and the failures were so many that Balker Brown abandoned the operation, saying: "It was of no use, peritonitis would alvays beat one." It was after his return from the Crimea that Spencer Wells, an old pupil of the Leeds Infirmary, upon lis appointment to the Samaritan Hospital, began, in 1858, that series of operations which firmly established the surgical treatment of ovarian tumours in favour, and by its success, and by the influence it had upon the treatment of other intraperitoneal conditions, opened up the whole field of abdominal surgery. The opposition to the surgical treatment of ovarian cysts was, as is well known, of the most bitter and inveterate kind, but Spencer Wells, by his simplicity of character, his unwavering integrity, and his sweet reasonableness in argument, wore down all antagonism. In the year 1880 - that is, in twentytwo years-lie had operated upon 1,000 cases, of which 768 recovered. During the first five year's one patient died in every three operations ; in the last two years one patient died in every ten. Writing in 1882 Spencer IVells said, "In Germany until quite recently ovariotomy was scarcely talked or thought of." Bill'otl,, in a lecture on ovariotoiny, said of Spencer Wells, "I shall willingly regard myself during my lifetime as his scholar." It is astonishing to recall that Spencer Wells's early success was achieved before the introctuction of antiseptic surgery. In the edition of his work on Ovarian and Uterine $T$ umour's, published in 1882, he endeavour's to estimate the difference in the mortality and morbidity of his cases as a result of the introduction of Lister's methods. It is therefore true to say that the whole of the immense progress that abdominal surgery and internal medicine have made in the last thirty year's has been due to the impulse and the investigations. of these two English surgeons, Spencer Wells and Lister. In all the pioneer work which made possible the infinite achievements of modern abdominal surgery, the contribution of Germany was precisely nothing. What part has she played in the later progress?

Let us take for a first inquiry the surgery of the gall bladder. The fullest account of the history of this extra. ordinarily interesting adventure in surgery is given by many German author's, of whom Langenbuch is, perhaps, the chief. On page after page of the story as told by him reference is made to the priority of German surgeons, and pride in German achievements is openly and frequently ex: pressed. A chapter of this author does duty not only as a contribution to the history of surgery but as a political pamplilet also. And, like much in the literature of politics, it is found on close examination to be acutely controversial, when it is not false. What are the facts? The first attempt to deal surgically with the gall bladder was made experimentally by Zambeccari in 1630. This observer ligatured the cystic artery and duct in a dog and removed the gall bladder. Tro months later the dog was lilled, and to the ligatured stump omentum and small intestine were found adherent. To Jean Louis Petit in 1743 is to be attributed the first suggestion of the surgical treatment of a distended gall bladder, and the first considered attempt. to deal operatively with it during the life of the patient: Over a century later, in 1859, Thudichum, in a paper on 
the "Pathology and treatment of gall stones," wrote: "In decided cases the surgeon should consider the propriety of planning and performing an operation for the extraction of these foreign bodies either in a direct manner or by forming a biliary fistula and adopting a lithotriptic pro. ceeding." In 1876 Thudichum and Maunder again broached the subject, and in 1878 Handfield Jones also proposed operation to a patient suffering from cholelithiasis. In the year 1867 an American surgeon, Dr. Bobbs, operated upon a case of abdominal tumour, diagnosed as probably one of ovarian cyst. The tumour proved to be a gall bladder, upon which Bobbs performed "lithotomy," removing several stones. But it is to Marion Sims that the credit is to be given for the first formulation of the opera. tion of cholecystotomy; the deliberate planning and the practical accomplishment of a procedure so carefully designed and so thorongh that Lawson 'Tait wrote, "The entire possibilities of the treatment of gall stones and distended gall bladder are exhausted in Dr. Marion Sims's original paper."

The first operation successfully performed in two stages is to be credited to Kocher, who in 1878 opened the abdomen, packed round the gall bladder with Lister's gauze, and six days later, when a barrier of adhesions had formed, opened the gall bladder and emptied it of stones.

An examination of all the lengthy literature of this subject, however, leaves one in no doubt that the most conspicuous merit for the pioneer work attaches to Lawson Tait. It was he who, basing his work upon the case of Marion Sims (a case of common duct obstruction, with jaundice, which proved fatal in a few days from haemorrhage), made of cholecystotomy a safe operation. Probably no operation of equal difficulty and severity was ever ushered into the world with so marvellous a series of successful cases. In 1884 Tait wrote: "I have performed the operation thirteen times, and all recovered." Up to the end of 1884 there had been performed in all the world twenty-eight operations, of which Lawson Tait did thirteen. Of the first 104 cases, he had operated upon 56; the whole of Germany then claimed 9 cases.

Cholecystectomy, the safe possibility of which had been shown experimentally two and a half centuries before, was first performed on July 15th, 1882, by Langenbuch. This is a very valuable addition to the resources of the surgeon, and its originator may well have had a legitimate pride in its inauguration. We cannot, however, hope to pay to his memory the luscious compliment he paid himself in the arrogant Prussian fashion and at inordinate length. If it is the only original contribution of Germany to the surgery of the biliary system, it is in truth a considerable one.

In the later developments France, England, and America may claim that they have played the greater part. 'To them are due not only those advances along the frontier of medicine which have disclosed to us the early symptoms of cholelithiasis, but also those technical perfections which have made precocious interference the safest and most prudent of all modes of treatment. Over against this recent work what has Germany to show? She has one man of large experience to put forvard-Kehr, and he is, indeed, a typical representative of his country. Tiehr has been a prolific writer and has published very full accounts of his technique and vesults. Kehr advises operation where there is obstruction of the cystic auct, infection of the gall bladder or ducts, or when stones are arrested in the common bile duct. A great many of the indications accepted by surgeons in other countries are omitted. For the purpose of access to the parts he has devised an incision, the Wellenschnitt; of great length, it begins in the epigastrium below the ensiform cartilage, extends downwards towards the umbilicus, then across the right rectus transversely for 2 in., and, finally, vertically down the rectus for 3 in. to 4 in. A very free exposure results. In all cases, or almost all, the gall bladder is removed, and the hepatic duct drained, often by a tube of T-shape, one arm of which goes upwards to the liver, the other downwards to the duo. denum. The methods thronghout are crude, coarse, heary. handed, lacking everything in the way of daintiness and refinement. 'This is expressed in the results, in which the mortality and morbidity are excessive. So far as the purely intellectual side of the work is concerned, in all Kehr's writings there is nothing at first hand. The inquiry as to the inaugural symptoms of cholelithiasis, the question of the early recognition of the presence of stoues the association of gall stones with other abdominal dis eases, appendicitis, intestinal stasis, in the relation of effect and cause-of these matters there is rarely an original observation. 'There is the same academic com pleteness of exposition which we find in all German work full, indeed tedious, accounts of anything and everything svearsome prolixity; but the facts and records are there in full. The only original piece of work done in tlre whole realm of cholelithiasis, in recent years in Germany, is that upon the formation of gall stones, by Aschoff and Bacmeister; it is important and accurate, but it touches only the fringe of the larger question of cholesterinaemia in which the chief work has been done by the French.

What is the history of the surgery of the stomach? The earliest account of gastric ulcer was given by Matthew Baillie in 1798. It is true that the disease is mentioned both by Galen and Celsus, and that there are records of probable cases, when haemorrhage or perforation occurred or fistula into the stomach developed, as early as the sixteenth century. But the first clear and illustrated anatomical description, accompanied by clinical histories, was given by Baillie. It is, however, to Cruveillier, who wrote in 1829 and 1830 , and up to the year 1838, that we give credit for the first fall and accurate descriptions of the pathology and clinical manifestations and treatment of this dissase. These descriptions are in the tenth and twentieth parts of his splendidly illustrated work on pathological anatomy. To Cruveilhier the famous German physician Ewald attributed the tirst careful and comprehensive description of gastric ulcer, and said that he "was the first to raise the gastric ulcer from a curiosity of the autopsy table to the dignity of a definite and recognizable pathological condition." In the year 1835 Cruveilhier gave the first suggestion of the development of cancer from a simple ulcer.

The earliest records of duodenal ulcer are found in connexion with stray cases, or in those where perforation or haemorrhage had occurred and cansed death. 'The earliest mention was by 'Travers in 1817 . Abercrombie in 1830 gave the first connected account of the disease, and recorded a few cases. In 1894 the first successful case of operation for a perforated ulcer was recorded by $\mathbf{H}$. P. Dean of London. In 1900 Weir of New York gave an excellent summary of all the cases of perforation then on record. But of duodenal ufcer as a cause of continued or recurrent dyspepsia, or as a pathological lesion to which were attached a series of symptoms capable of recognition during life, there is nothing. The first ascription of a group of symptoms to the definite structural lesion in the duodenum is to be placed to the exclusive credit of English medicine.

The development of the surgery of the stomach has been one of the most brilliant and most fascinating of all the recent conquests of our art. So-long ago as 1810 it had been shown by Merrem that the removal of a part of the stomach in dogs could be followed by recovery. This experiment was repeated and multiplied in 1876 by Gussenbauer and Winiwarter. It is, lrowever, to a French surgeon, a most dexterous operator, that the credit is due for the first attempt, albeit unsuccessful, to remove a part of the stomach for cancer. On April -9th, 1879, Péan of Paris carried out the first pylorectomy for malignant disease. The operation was repeated, again with a fatal result, by Rydygier in 1880 . It was on February 8th, 1881 , that Billroth in Vienna performed the first successful gastric resection for carcinoma. I have seen the specimen, which consists of the pylaric end of the stomach; it measures about 3 in. in length in its present state. It was the work of Billroth and of his assistants Mikulicz and Wölfler that proved the surgical treatment of carcinoma of the stomach to be feasible. Billroth clearly laid down the principles and the technical details to be observed in all gastric operations. All later work was made possible by his work, and we may safely reckon his contribution to this branch of surgery as the finest of the many notablo achievements in the life of this great surgeon. It fell to Wölfler, while assistant to Billroth, to perform the first operation of gastro-enterostomy, on September 27th, 1881. The patient suffered from a malignant obstruction of the pylorus, and it was Wölfer's intention to porform rescc!ion. This was found impossible, and the abdomen was about to be closed when Nicoladoni, who was assisting, suggested 
that the jejunum should be united to the stomach and an opening between the two viscera made to relieve the pyloric obstruction caused by the growth. The original operation was of the "anderior" type. Union of the jejunum into the posterior surfaces of the stomach was first suggested by Courvoisier of Basle, and rou Hacker of Innsbruck.

The great surgical accomplishments in the last quarter of a century have bcen concerned with the simple diseases of the stomach, with chronic ulcer and its complications. The first gastro-enterostomy for chronic obstructive ulcer was performed in 1892 by Doyen of Paris. It is to the advocacy and to the marvellous technical skill of this surgeon that we must attribute the general recognition of the value of surgical measures in cases of chronic gastric disease and the recognition of gastro-enterostomy as a "drainage operation." "The surgery of perforating ulcer of the stomach began with Mikulicz, whose first suggestion dates from 1880. Between the years 1885 and 1893 Mikulicz operated upon thirty-five cases with thirty-four deatlis. This is to be considered, taking into account the early period of this work, as the saving of one life, rather than the loss of many.

The literature emitted by Germany upon the subject of gastric diseases is vast in quantity, prolix and turgid in style, lacking insight and interest, and almost utterly devoid of inspiration or original thought. It is, however, a complete record of the progress made and of the knowledge gained by all the workers in every corner of the field. The Germans are seen in their most characteristic phase as gleaners and harvesters. The seed has been sown by others; it is they who have guarded the crop, garnered it, gleaned every straw of it, and stored it in vast and ugly chambers. Gastric ulcer is a comparatively rare disease, of few but clear-cut symptoms. Around this simple matter the German clinicians have weaved a web of rhetoric which has encumbered it and swathed it beyond recognition. And they have borrowed freely from a riotous but rank imagination bereft of facts, and have insulted the intelligence of those who could not agree with them. The literature of Germany on such a subject as gastric ulcer reminds me irresistibly of Hans Andersen's delightful story of the "Emperor's New Clothes." Around this simple disease their physicians weaved, with unceasing industry, garments of a material every thread of which they declared to be of the rarest and finest quality, they told all the world of the beauty and superb texture of these royal robes; so confident and magisterial were their lond assertions and so complete the trickery by which they imposed upon all spectators, saying that only those of virtue could see.the wonderful garments, that, as in the story, the crowd was humbly acquiescent. But at last the little child, the surgeon, came along and cried: "But he has got nothing on." And the whole artificial fabric was torn away, and the imperial ulcer was seen for what it was in all its naked ugliness.

\section{SURGery OF THE Brain aNd CORD.}

The development and progress of cerebral surgery in the last century would certainly be considered by the older physicians, could they learn of it, as the most incredible achievement of all. To them the skull and its contents wero sacred and inviolable. Aristotle had spoken disparagingly of the brain, saying it was a mere cooling apparatus, and trephining operations had been not un. common even in prehistoric times. But by the mediaeval physicians the brain was looked upon as the seat of the soul, and no profane hand might be laid upon it. When, however, the Renaissance came, with its astonishing development of physical science as well as of art, the work of Mondinus and Vesalius opened the path for all later explorers. What Harvey achieved for physiology was almost equalled by the work of Thomas Willis on the nervous system. As Victor Horsley said, these researches " exlibit an extraordinary grasp of the function (and its corresponding relation to structure) of the nervous system generally." Willis's work ought to have abolished for ever the old mystical beliefs as to the function of the brain. He was the first to allocate definite functions to distinct parts of the nervous system and to assert that the excitation of the cerebral cortex passed into the substance of the brain and theuce into the spinal cord and nerves. The wo'k of Thomas Willis was, unhappily, ignored completely, though as we look back upon it we are inclined to agree with Horsley, who wrote "that it was due to Willis that probably the greatest advance gained in psychology ever since it became a science, the localization of function to distinct parts of the nervous system," was made. The first of those who sought by the method of experimental research to discover the secret of the functions of the brain was Flourens in 1826. His investigations dealt both with the cerebrum and the cerebellum, and were of high value, not only as examples of a new method, but also because of the positive, though limited, conclusions upon many matters, which as a result of his work he was entitled to draw. But even he, writing more than a century and a half after Willis, asserted that the brain worked as a whole, and that separate specitic functions could not be allotted to its several constituent parts. Indeed, the universally accepted opinion up to the year 1861 was that the brain acted as other organs acted, its function being carried out by an equal working of all its parts. In this year Broca, as the result of his inquiries into the pathological anatomy of certain cases of aphasia, came to the conclusion that the faculty of articulate speech depended upon the integrity of a definite and limited area of the cerebral cortex. Broca's discovery was revolutionary; it involved a complete reversal of former opinions and judgements, and it opened up afresh the whole ques. tion of the function of the cortex of the brain. Hughlings Jackson in 1869 was the first to assert that the convolutions of the brain could be divided up into separate areas, each having its own restricted and unchangeable funclion. He based his opinion upon observations made to correlate the clinical symptoms manifested during the life of the patient with the organic lesions of the brain discovered after death. In 1870 Fritsch and Hitzig demonstrated by animal experiments that by the electrical stimulation of certain areas upon the cortex co-ordinated movements, in distinct groups of muscles, on the opposite side of the body, could be produced. These observations were important, but the work of supreme significance in cerebral localization was done by Ferrier, and published in 1873. Ferrier's researches were undertaken to test experimentally the conclusions reached upon clinical and pathological grounds by Hughlings Jackson. The result is known to all the world. Ferrier's investigations established firmly and finally the knowledge that there are points in the cortical matter of the brain definitely related to the motor and sensory functions of certain parts of the body. The way now was cleared for the surgeons, for Lister had afforded them safety, and Hughlings Jackson and Ferrier gave them guidance. The pioneer work in this direction was exclusively of British origin. One of the most dramatic occurrences in the whole history of surgery must surely have been the reading on August 9th, 1888, of a paper on the "Surgery of the brain and spinal cord" by W. Macewen of Glasgow. Cerebral surgery seemed to spring Minerva-like into the world, complete at every point. Macewen told of his first case in July, 1876; it occurred in a boy who developed an abscess in the immediate vicinity of Broca's lobe, as the result of an injury to the skull. Consent was not given to the operation urged by Macewen, notwithstanding the assumption by himself of the sole responsibility of advising and performing the operation; and the boy died. Macewen tells how "after death the friends acquiesced in the proposal to have the operation performed just as it would have been had permission to do so been granted during life. The skull was trephined, the brain exposed, and an instrument was introduced through the third frontal convolution for half an inch, when pus flowed through the incision, proving the accuracy of the diagnosis and giving poignancy to the regret that the operation had not been permitted during life. The abscess, about the size of a pigeon's egg, was situated in the white matter of the bases of the second and third frontal convolutions." In this case the precise spot in the brain which the abscess occupied was accurately determined from the localizing phenomena induced by the focal lesion.

Macewen's first successful cases-one of abscess and one of tumour of the frontal lobe--occuired in 1879. In the paper to which 1 have referred there were recorded 21 cerebral cases (exclusive of fracture of the sliull with brain lesions), with 18 recoveries and 3 deaths. Of those who died all were in extremis when operated upon. It the time the paper was read 16 of the 18 were still alive; 
one had died eight years after operation, and one forty. seven days after operation of tuberculous enteritis.

The record of the work achieved by this surgeon, working alone upon new problems and in a new field long before other minds had begun to stir, is one of the greatest triumphs in the history of scientific surgery. In the year 1884 Bennett and Godlee reported a case of cerebral bumour treated by operation, and in 1886 Victor Horsley keported three cases of cerebral surgery to the British Medical Association.

Great Britain may therefore make an undeniable claim to priority in respest both of the scientific work which made operation upon the brain possible and purposeful and of the procedures by which such operations were carried out with safety and accuracy. Germany here also has been a follower, not a founder. Her entrance into this field was of later date than that of the British, French, and Italian physicians and surgeons, but her work in it has been arduous and helpful.

The development of the surgery of the spinal cord was also dependent upon early experimental research. Galen, as is well known, had shown that there must be nerves of sensation and nerves of motion. Willis had made it certain that the nerves did convey sensation " and instincts to movements," but, as Sir Victor Horsloy says, "no further determination as to the particular part of the wervous system which might be occupied in providing for such transmission of sensations and movements was made until 1811, when Sir Charles Bell, by his numerous investi. gations, was led to believe that separate parts of the brain and spinal cord subserved these two functions." Sir Charles Bell knew, of course, that the spinal nerve had two roots, anterior and posterior; he found by experiments that it was irritation of the anterior roots only that gave rise to the morements of the muscles. He says: "I now. saw the meaning of the double connexion of the nerves with the spinal marrow." Bell's work was the first to prove that there was undoubtediy a principle of localization of function in the nervous system. When it had once been shown that this localization of function existed in the conducting nerve channels it was not difficult to see that the same difference must exist in those central parts to which, and from which, the nerves must pass. The surgery of the spinal canal was inaugurated by Sir Victor Horaley, who in 1887 was the first to open the spinal dura mater and to remove a tumour of the cord. In December, 1888, Bennett first divided the posterior nerve roots in a case of inveterate sciatica. In 1889 J. L. Faure performed the same operation for the relief of agonizing pain in a case of cancer of the uterus. Foerster's operation, the division of the posterior spinal nerve roots for the treatment of gastric crises and spastic paralysis, based largely upon the work of Sherrington and Head, dates from 1908.

\section{Conclusion.}

What, then, has been Germany's part in all the astounding progress of modern surgery? It has been the same in surgery as in every other science. Almost all fundamental discoveries in science, Dagald Clerk tells us, have originated in England, France, and Italy. In capacity for original thonght the German mind is lacking. The brilliant and happy inspiration, the penetrating insight, the new vision are things for which we seek almost in vain in all German scientific literature. The fertile new thought giving a fructifying impulse to the work of other 3 is rarely indeed of German origin. The German mind is of quite a different order. It is avaricious, industrious, methodical; it collects, if it does not accurately appraise, the work of others. It tabulates and registers and explains; it furnishes an intricate analysis, and illustrates by copious reference any subject with which it may deal. The new idea, originating almost always elsewhere, is given eager hospitality, is dissected and discussed at inordinate length; it may be put into practice with various alterations of technical procedure, and before long be claimed as a home product. For this act of intellectual dishonesty many of the German writers were not to blame; for a study of the literature of almost any subject in medicine chosen at random will show the amazing infrequency of any reference to the English or American literature, and very few indeed to the French. Thus in Riegel's work, the article on ulcer of the stomach has four and a half pages of references, seven references are to English writers, five are tc papers by Riegel himself.
The name of Brinton is not even mentioned in this list, and yet it is probable that in his small book there is more of the truth of the matter of gastric diseases than in all the interminable treatises published by all the German physicians since his death. This almost exclusive reference by German writers to the works of their own countrymen was greatly helped by their publishers. In the last few years I have heard more than once from friends of my own in the medical profession in Italy, in Spain, and in Norway, that it was impossible to obtain from an English or American publisher a copy of any medical work on approval. A surgeon, desirous of seeing a new work in any special department of surgery, could only do so by purchasing the book outright and taking his chance as to the contents being to his liking. Any German publisher would send him all the books or journals he desired to see on approval. The copies of new German works on medicine were always sent to the editors of foreign journals for review. A new medical work in English was rarely, if ever, sent to Scandinavian countries, to Spain or to Italy, and to France or to Germany only in the case of a work of outstanding importance. To put this matter quite briefly, reference could always and quite easily be made by foreign physicians or surgeons to works published in Germany. It was difficult to hear of English works, and almost impossible to obtain them except by a speculative purchase. To the claims which Germany makes for intellectual supremacy we may therefore, speaking of scientific surgery, retort by a firm and flat denial. Not one single discovery of the first importance in the science or in the art of surgery can be placed to the credit of Germany. Nor, if we omit the Semitic element in the Germany of to-day, should we expect this to be the case. For the German mind is deductive; it is patient, laborious, massive; but it is not original. The German is not an innovator, but a renovator; not an explorer, but an exploiter; not a creator, but a collector.

\section{A RECONSIDERATION OF THE PRINCIPIES AND METHODS OF HUGH OWEN THOMAS."}

\section{SOME REFLECTIONS ON THOMAS'S SPLINTS AND PRACTICE.}

By J. LYNN THOMAS, C.B., C.M.G., F.R.C.S.,

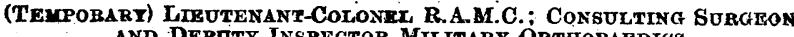
AND DEPJTY INSPECTOR MHLITARY ORTHOPAEDIC'B,
WESTERN Comarand.

I INDICATED in my first communication (July 15th, 1916) some of the many new resources which the genius of Hugh Owen Thomas devised for the improvement and advancement of a branch of surgery which since his time has failed to get its proper place in the sun owing to the birth, rapid growth, and brilliant youth of modern abdominal surgery. Nevertheless, Thomas's boots for the prevention and the correction of flat feet; Thomas's wrench for dealing with congenital and acquired deformities, such as club feet, neglected or unreduced Colles's fractures, and Thomas's "splints" for treatment of injuries, deformities, and diseases of the lower extremities very slowly but surely found a place in the records of the progress of orthopaedic surgery.

One of the factors which made Thomas's success in this department so unique was the personal attention he gave to every detail in the construction of the many derices or machines which he invented; it would have been im. possible for him in his busy life in pre-telephone days to follow the orthodox but ineffectual fashion of resting dependent upon the services of a surgical instrument maker living at a distance from his consulting-rooms. He solved the problem by what appears to be a true inspiration-he had workshops built closely attached to his consulting-rooms. It was only by this means that he was enabled to carry out the enormous amount of experimental work entailed in working out the models of ortho. paedic appliances; when he had perfected them he was able to recommend them with confidence to the profes. sion. Orthopaedic surgery owes a lasting debt to Thomas for this bold if heretical act; for him it was the only way 